\title{
A MÍDIA E A EXPERIMENTAÇÃO COM ANIMAIS NO ENSINO BÁSICO DE CIÊNCIASS NO ESTADO DE SÃO PAULO: UMA ANÁLISE DA COBERTURA FEITA POR JORNAIS IMPRESSOS NAS DÉCADAS DE 1960 E 1970
}

\author{
Danilo MAGALHÃES \\ Luisa MASSARANI ${ }^{2}$ \\ Jessica NORBERTO ROCHA ${ }^{3}$
}

\begin{abstract}
Resumo
O movimento renovador introduziu atividades práticas ao ensino de ciências nas escolas brasileiras durante as décadas de 1950 a 1970, entre elas a experimentação animal. O objetivo deste artigo foi analisar como jornais do período retrataram as práticas de experimentação animal no ensino básico de ciências em São Paulo e como as controvérsias em torno do assunto foram veiculadas. Em nosso levantamento, identificamos e analisamos 109 registros de 11 jornais das décadas de 1960 e 1970, seguindo procedimentos teóricometodológicos para o uso da imprensa na História da Educação. Nos anos 1960, os jornais mostraram que os trabalhos com animais chamavam a atenção do público visitante de feiras de ciências escolares e justificaram sua existência como parte do aprender ciência. Na década de 1970, observamos a recomendação de evitar experimentação animal e a presença de entidades regulando-a. Os jornais expuseram as críticas dos que consideravam as experimentações arriscadas para animais e estudantes, bem como a posição de educadores e entidades científicas na defesa das práticas.
\end{abstract}

Palavras-chave: Vivissecção. Ensino de Ciências. Feiras de Ciências. História da Educação. Imprensa.

\footnotetext{
${ }^{1}$ Mestre em Antropologia Social pela Universidade Federal do Rio de Janeiro (UFRJ) e graduado em Ciências Sociais também pela UFRJ. ORCID: https://orcid.org/0000-0001-7432-9392.

E-mail: danilomagalhaes@protonmail.com.

${ }^{2}$ Doutora em Educação, Gestão e Difusão em Biociências pela Universidade Federal do Rio de Janeiro (UFRJ), Bolsista Produtividade do CNPq 1C. Cientista do Nosso Estado da Faperj. ORCID: https://orcid.org/0000-0002-5710-7242. E-mail: luisamassarani7@gmail.com.

${ }^{3}$ Doutora em Educação pela Universidade de São Paulo (USP), mestre em Divulgação Científica e Cultural pela Universidade Estadual de Campinas (Unicamp) e graduada em Letras pela Universidade Federal de Minas Gerais (UFMG). ORCID: https://orcid.org/0000-0002-9754-3874.

E-mail: jessicanorberto@yahoo.com.br.
} 


\title{
THE MEDIA AND THE ANIMAL EXPERIMENTATION IN BASIC SCIENCE EDUCATION IN THE STATE OF SÃO PAULO: AN ANALYSIS OF COVERAGE BY PRINTED NEWSPAPERS IN THE 1960S AND 1970S
}

\author{
Danilo MAGALHÃES \\ Luisa MASSARANI \\ Jessica NORBERTO ROCHA
}

\begin{abstract}
The renewal movement introduced practical activities to science teaching in Brazilian schools during the 1950 s to the 1970 s, including animal experimentation. The purpose of this article was to analyze how newspapers of the period portrayed the practices of animal experimentation in basic science education in São Paulo and the way the controversies around the subject were broadcast. In our study, we identified and analyzed 109 records from 11 newspapers from the 1960s and 1970s following theoretical-methodological procedures for the use of the press in the History of Education. In the 1960s, newspapers showed that work with animals drew the attention of visitors to school science fairs and justified their existence as part of learning science. In the 1970s, we observed the recommendation to avoid animal experimentation and the presence of entities regulating it. The newspapers exposed the criticisms of those who considered experimentation risky for animals and students, as well as the position of educators and scientific entities in the defense of the practices.
\end{abstract}

Keywords: Vivisection. Science Education. Science Fairs. History of Education. Press. 


\title{
EDUCAÇ̃̃̃
}

\section{LOS MEDIOS DE COMUNICACIÓN Y LA EXPERIMENTACIÓN CON ANIMALES EN LA EDUCACIÓN CIENTÍFICA BÁSICA EN EL ESTADO DE SAN PAULO: UN ANÁLISIS DE LA COBERTURA DE LOS PERIÓDICOS IMPRESOS EN LAS DÉCADAS DE 1960 Y 1970}

Danilo MAGALHÃES

Luisa MASSARANI

Jessica NORBERTO ROCHA

\begin{abstract}
Resumen
El movimiento de renovación introdujo actividades prácticas en la enseñanza de las ciencias en las escuelas brasileñas durante los años 1950 y 1970, incluida la experimentación con animales. El propósito fue analizar cómo los periódicos de la época retrataron las prácticas de experimentación animal en la educación científica básica en San Paulo y cómo se transmitieron las controversias en torno al tema. En nuestra investigación, identificamos y analizamos 109 registros de 11 periódicos de las décadas de 1960 y 1970 siguiendo procedimientos teórico-metodológicos para el uso de la prensa en la Historia de la Educación. En los 1960, los periódicos mostraron que el trabajo con animales atraía la atención de los visitantes de las ferias de ciencias escolares y justificaba su existencia como parte del aprendizaje de las ciencias. En la década de 1970 observamos la recomendación de evitar la experimentación con animales y la presencia de entidades que la regulan. Los periódicos expusieron las críticas de quienes consideraban arriesgada la experimentación para los animales y los estudiantes, así como la posición de educadores y entidades científicas en la defensa de las prácticas.
\end{abstract}

Palabras clave: Vivisección. Enseñanza de las Ciencias. Ferias de Ciencias. Historia de la Educación. Prensa. 


\section{Introdução}

O ensino de ciências no Brasil passou por importantes reformulações nas décadas de 1950 a 1970. Preocupados com a educação, o papel da ciência e o desenvolvimento nacional, educadores, cientistas e divulgadores da ciência brasileiros engajaram-se no esforço de torná-lo mais dinâmico e atrativo por meio de métodos que enfatizavam a vivência da investigação científica pelos alunos com atividades de experimentação (CASSAB, 2015). As transformações ocorridas na educação em ciências nos Estados Unidos nos períodos pós-Segunda Guerra Mundial e Guerra Fria, com a relevância que ciência e tecnologia adquiriram no contexto, também influenciaram, por meio das políticas externas norte-americanas, essas propostas de reformulação (MANCUSO; LEITE FILHO, 2006; KRASILCHIK, 2000; NORBERTO ROCHA et al, 2020). Os materiais didáticos produzidos nesse período (muitos dos quais importados dos Estados Unidos, traduzidos e adaptados ao contexto nacional) valorizavam o método científico experimental como uma importante estratégia pedagógica no ensino de ciências de forma a desenvolver nos estudantes atitudes vistas como científicas quando confrontados com problemas (VALLA et al., 2014).

Algumas instituições tiveram grande importância nas ações e propostas deste período. O Instituto Brasileiro de Educação, Ciência e Cultura (IBECC), em especial a seção de São Paulo, foi uma das principais. Criado em 1946 como uma comissão brasileira da Organização das Nações Unidas para a Educação, a Ciência e a Cultura (UNESCO), o IBECC realizou experiências inovadoras como a organização de concursos, clubes e feiras de ciências, a tradução e edição de livros e a elaboração de novos materiais didáticos e kits de experimentação científica (ABRANTES, 2008). Os Centros de Ciências, criados em 1965 nas seis principais capitais brasileiras da época, também tiveram um papel importante na capacitação de professores e na elaboração de novos materiais e métodos para o ensino de ciências (NORBERTO ROCHA et al, 2020). Entre as ações adotadas pelo IBECC e pelos Centros de Ciências estão as feiras de ciências organizadas durante as décadas de 1960 e 1970 (MANCUSO; LEITE FILHO, 2006; ABRANTES, 2008). As feiras de ciências foram especialmente fortes em São Paulo com o protagonismo do IBECC e receberam ampla cobertura na imprensa brasileira (MAGALHÃES et al., 2019). Tomadas em conjunto, essas ações e propostas de reformulação são descritas na literatura consultada como um "movimento de renovação do ensino de ciências" (cf. ABRANTES, 2008; BORGES et al., 2012; VALLA et al., 2014; CASSAB, 2015). 
A mídia e a experimentação com animais no ensino básico de ciências no estado de São Paulo: uma análise da cobertura feita por jornais impressos nas décadas de 1960 e 1970

\section{O incentivo à experimentação com animais}

Entre as distintas atividades de experimentação propostas pelo movimento como forma de desenvolver habilidades e aprendizagem sobre as ciências e a metodologia científica, estavam os experimentos com animais. Essa prática foi considerada parte fundamental da pesquisa científica e educação em ciências pelos educadores envolvidos no movimento, como se vê no livro Práticas de ciências: conteúdo e didática (SANTOS, 1968), um guia de ensino que circulou entre educadores no período.

Segundo o autor, Newton Dias dos Santos, as instituições que davam oficinas de aperfeiçoamento aos professores de ciências durante o período ensinavam práticas de dissecação de animais a esses professores para posterior reprodução em sala de aula com os estudantes, partindo do pressuposto de que "só se aprende lidando, diretamente e de primeira mão, com seres vivos e com os fenômenos que neles se passam" (SANTOS, 1968, p.69). Silva (2015) confirma esse dado ao recuperar o testemunho de um professor de ciências envolvido com o Centro de Ensino de Ciências do Nordeste (CECINE) nas décadas de 1960 e 1970, segundo o qual "ao dissecar o animal na aula, ensinávamos teoria com base no que eles estavam vendo" (SILVA, 2015, p.126). Abrantes (2008), por sua vez, mostra que o IBECC já incluía materiais de dissecação de animais nos kits de experimentação que fornecia a algumas escolas estaduais de São Paulo desde 1955.

Os livros didáticos de Biologia das décadas de 1960 e 1970 também ajudam a entender as concepções curriculares sobre a experimentação animal no período. O Biological Science Curriculum Study (BSCS), livro produzido nos Estados Unidos no contexto de reformulação curricular e introduzido no ensino secundário brasileiro através dos acordos MEC-USAID, continha propostas de experiências com seres vivos. O BSCS foi traduzido pelo IBECC e adaptado para o país em uma versão azul, em dois volumes, e uma verde, em três volumes. Publicado a partir de 1965, o BSCS enfatizava a experimentação como parte dos conteúdos, metodologias e formas de ensinar e aprender Biologia (SILVA, 2020). Na introdução, por exemplo, é possível ler a intenção dos autores de apresentar a Biologia como "uma aventura no campo das ideias, na qual as ideias se referem a observações específicas e às experiências sobre seres vivos (BSCS, 1969, p.12). O guia de laboratório que acompanhava o livro previa, entre outros pontos, a necessidade de aprender "a lidar com os organismos vivos" (BSCS, 1969, p.239). O guia previa igualmente alguns cuidados necessários para o caso das escolas que tivessem laboratórios com animais: providenciar água e alimentação adequada, manter as gaiolas limpas e bem fechadas, e, reconhecendo o "privilégio" de tê-los em um laboratório, "tratá-los com humanidade", usando anestesia quando necessário matá-los 
(BSCS, 1969, p.240). A versão verde do BSCS, publicada durante a década de 1970, continha exercícios de vivissecção de sapos para estudo de sua fisiologia (BSCS, 1976a, p.113; BSCS, 1976b, p.107) e de exame de comportamentos de animais (BSCS, 1976a, p.185).

Na década de 1970, a experimentação com animais no ensino básico recebeu uma legislação específica. Em São Paulo, em 1976, foi sancionada a Lei Estadual 1.122, proibindo as práticas de "dissecção e vivissecção de animais em laboratório de estabelecimentos de ensino de $1 .{ }^{\circ}$ Grau"4 em todo o estado. Em 1979 foi sancionada a primeira legislação federal brasileira que trata sobre o uso de animais em pesquisa científica, Lei $6638^{5}$, que também incluiu medidas restritivas à experimentação com animais no ensino de ciências. A implementação de leis regulando essas práticas aponta para a existência de uma controvérsia relacionada a elas. Nesse sentido, uma demanda necessária é entender melhor como se dava o uso de animais no ensino básico brasileiro, como se desenvolveu a controvérsia que resultou nas legislações e qual o papel que os meios de comunicação de massa - em especial os jornais - tiveram nessa polêmica.

De acordo com Araújo e Gatti Júnior (2002), Bastos (2002), Schelbauer e Araújo (2007), Zanlorenzi (2010), Campos (2012), Arnaut de Toledo e Skalinski Junior (2012), Pasquini e Arnaut de Toledo (2014), entre outros pesquisadores, a imprensa não pedagógica é uma importante fonte para a escrita da História da Educação. Os jornais são veículos importantes de ideias, valores, projetos políticos e representações sociais. Por meio deles, são veiculados debates, discussões e polêmicas de uma época. Suas páginas carregam condições e motivações que levam à decisão de tornar algo notícia (e silenciar sobre outros fatos), e é a imprensa um importante ator político na definição e circulação daquilo que importa em determinado momento histórico (LUCA, 2006; CAMPOS, 2012; ARNAUT DE TOLEDO; SKALINSKI JUNIOR, 2012).

Munidos das ferramentas metodológicas adequadas, pesquisadores em História da Educação têm demonstrado como os jornais, submetidos à crítica documental, permitem analisar contextos e discursos educacionais, podem revelar representações correntes sobre a escola e a profissão docente e permitem a problematização das estratégias utilizadas por determinados grupos na consolidação de políticas públicas educacionais. Eles possibilitam também verificar sua utilização como veículos educativos centrais em processos civilizadores da população, bem como revelar os embates próprios ao campo pedagógico que ecoam pelo país por intermédio dos processos de confecção e circulação

\footnotetext{
${ }^{4}$ Disponível em: <https://www.al.sp.gov.br/repositorio/legislacao/lei/1976/lei-1122-21.10.1976.html> Acesso em: 07 out. 2020.

5 Disponível em: <https://www2.camara.leg.br/legin/fed/lei/1970-1979/lei-6638-8-maio-1979-366514publicacaooriginal-1-pl.html> Acesso em 22 mai.2020.
} 
dos jornais (BASTOS, 2002; ZANLORENZI, 2010; CAMPOS, 2012; ARNAUT DE TOLEDO; SKALINSKI JUNIOR, 2012; PASQUINI; ARNAUT DE TOLEDO, 2014).

As críticas ao ensino "livresco" tradicional e as propostas de novos métodos de "ensino experimental" feitas pelo movimento estiveram presentes nos jornais do período de renovação do ensino de ciências (MASSARANI et al., 2011). Educadores, cientistas e divulgadores científicos tocados pelas ideias do movimento ocupavam espaços na imprensa e se engajaram nos debates sobre o papel da ciência e da escola em uma sociedade em rápido processo de industrialização. Assim, analisar a cobertura que os jornais realizaram do ensino de São Paulo é relevante por conta da repercussão que as ações do movimento renovador do ensino de ciências tiveram no estado, particularmente por meio da seção paulista do IBECC, que reuniu figuras importantes na história da divulgação científica e do ensino de ciências no país, como o divulgador científico José Reis (ABRANTES, 2008).

Apesar de conhecermos evidências de livros didáticos e materiais de formação de professores, ainda é pequena a literatura que explora a presença de experimentos com animais - especialmente animais vivos - no ensino básico brasileiro nas décadas de 1950 a 1970. Similarmente, não encontramos na literatura a existência de um estudo sobre a Lei 1.122 de 1976 que regulamentou o uso de animais na educação no estado de São Paulo, acompanhando os debates nacionais sobre o assunto. Nesse contexto, o objetivo deste estudo é analisar a maneira como jornais das décadas de 1950 a 1970 retrataram as práticas de experimentação animal realizadas no ensino básico de ciências em São Paulo, bem como a forma como as controvérsias em torno do assunto foram veiculadas pelos jornais.

\section{Metodologia}

Para este estudo, realizamos um levantamento de jornais no acervo da Hemeroteca Digital Brasileira da Biblioteca Nacional (BNDigital) ${ }^{6}$. A BNDigital constitui-se como uma fonte de grande relevância, uma vez que permite o acesso gratuito, por meio da Internet, a um amplo acervo, que inclui diversos jornais. Também consultamos os acervos digitais de O Globo, O Estado de São Paulo e Folha de São Paulo, os três jornais mais representativos em tiragem e alcance no país e que têm seus próprios acervos.

\footnotetext{
${ }^{6}$ Disponível em: <http://bndigital.bn.gov.br/> Acesso em: 11 set. 2020.
} 
A fim de realizar o levantamento, iniciamos as buscas utilizando as expressões "dissecação 7 de animais" e "vivissecção" nas décadas de 1950 a 1970. A escolha desses termos se justifica por conta das práticas de dissecção e vivissecção terem sido consideradas as mais polêmicas e objetos de enfoque nas legislações consultadas. O termo dissecção refere-se à ação de seccionar partes do corpo ou órgãos de animais mortos para o estudo de sua anatomia. O termo vivissecção refere-se, originalmente, à intervenção cirúrgica em animais vivos, anestesiados ou não, para estudo de aspectos anatomo-fisiológicos. Com o tempo, o termo vivissecção acabou adquirindo o sentido mais geral de qualquer intervenção em animal vivo com propósitos científicos, ou seja, a fim de testar hipóteses, prover respostas ou validar resultados (RAMIRO, 2011).

Outras buscas que apresentaram bons resultados para a ampliação do corpus e uma análise sobre outros tipos de usos de animais no ensino foram as combinações dos termos "animais" e "cobaias" com "ensino de ciências", "educação em ciências", "feira de ciências", "clube de ciências". Também realizamos buscas com os termos "Lei 389", "Lei 1.122", "Francisco Antônio Coelho" - números do Projeto de Lei e da Lei aprovada em 1976 que regulamentou o uso de animais no ensino de São Paulo e o nome do deputado autor do projeto. Outra estratégia de busca importante foi a utilização da expressão "feira de ciências" na mesma base e a seleção dos registros que mencionam algum tipo de experimento com animais nas feiras de ciências do estado de São Paulo, realizadas nas décadas de 1960 e 1970.

Ao todo, foram levantados 109 registros em 11 jornais entre os anos 1960 e 1979. São estes: Folha de São Paulo (SP) (26 registros), O Estado de São Paulo (SP) (19 registros), Jornal do Brasil (RJ) (18 registros), O Globo (RJ) (14 registros), Jornal do Commercio (RJ) e Correio Braziliense (DF) (5 registros cada), Diário da Noite (SP) e O Cruzeiro (RJ) (4 registros cada), O Fluminense (RJ) e O Jornal (RJ) (3 registros cada), A Tribuna (SP), Diário de Notícias (RJ) e Diário de Pernambuco (PE) (2 registros cada) e Manchete (RJ), Correio da Manhã (RJ) e Diário do Paraná (PR) (1 registro cada). Os 109 registros encontrados dividem-se em 81 matérias e 28 cartas de leitores enviadas aos jornais. Não foram encontrados registros na década de 1950 relativos ao uso de animais no contexto do ensino de ciências, apenas registros dos termos "dissecação" e "vivissecção" aplicados como metáfora em outros contextos. Portanto, nosso período de análise são as décadas de 1960 e 1970.

\footnotetext{
${ }^{7}$ As grafias dissecação e dissecção são aceitas. Na época, entretanto, usava-se exclusivamente o primeiro formato.
} 
Gráfico 1 - distribuição dos registros encontrados entre 1960 e 1979

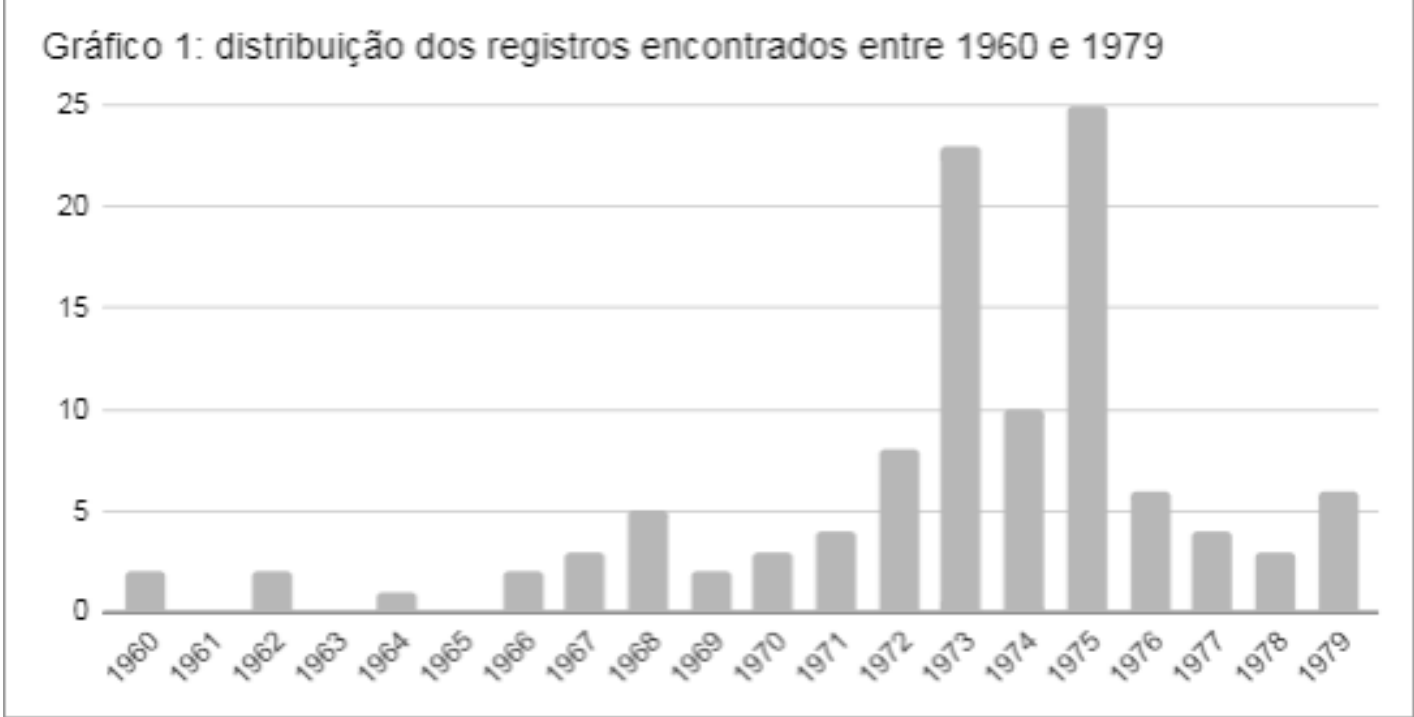

Fonte: criado pelos autores.

Para a análise da amostra, os registros foram separados em dois conjuntos. O primeiro conjunto foi composto de matérias que retratam o uso de animais no contexto do ensino de ciências. Arnaut de Toledo e Skalinski Junior (2012) observam o estudo dos jornais como meio de compreender as articulações entre teoria e prática educacional, ampliando o conhecimento das práticas educativas e das discussões em torno das legislações da educação. Como forma de melhor compreender o envolvimento de animais no ensino básico de São Paulo e os sentidos que os acompanham, analisamos os registros observando os animais utilizados, os tipos de usos e como esses usos foram descritos pelos jornais: quais adjetivos foram utilizados, qual o tom da cobertura e como os jornais relacionaram esses usos aos métodos e objetivos do ensino de ciências.

O segundo conjunto foi composto de registros que cobrem o desenvolvimento da controvérsia sobre o uso de animais no ensino básico. Arnaut de Toledo e Skalinski Junior (2012) observam que a análise da imprensa permite a composição de um painel vivo e revelador de personagens, com seus discursos impressos, estratégias e intenções de atuação na esfera pública. A análise da presença de conflitos e embates próprios ao campo pedagógico nos jornais possibilita a compreensão da ressonância dos discursos educacionais dentro e fora do universo escolar, bem como das representações sobre métodos e objetivos do ensino (ZANLORENZI, 2010). Nesse sentido, analisamos as opiniões contrárias e favoráveis à prática e a maneira como as matérias mencionam os processos institucionais e legislativos de debate e normatização sobre o tema. A separação deste conjunto nos permitiu observar como se deu o debate público sobre o uso de animais no ensino 
básico de ciências, especialmente no tocante às práticas de dissecção e vivissecção, e o contexto que justificou as legislações sobre o tema. As 28 cartas de leitores publicadas pelos jornais estão incluídas neste conjunto. Analisamos sua autoria (se foram escritas por pais de alunos, estudantes, professores ou outros), seu posicionamento (favoráveis ou contrárias às práticas) e as justificativas para tais posicionamentos. Observamos também como os atores envolvidos no debate e o próprio jornal buscaram mobilizar essas cartas no interior da controvérsia em torno da experimentação com animais no ensino básico de São Paulo.

\section{Os experimentos com animais nas feiras de ciências de São Paulo segundo os jornais}

Todos os registros jornalísticos de experimentos com animais realizados em contexto de ensino básico de ciências identificados referem-se a trabalhos apresentados por estudantes nas feiras de ciências organizadas em São Paulo durante as décadas de 1960 e 1970. Vale destacar que não restringimos nossa busca a esse contexto, porém ele se ressaltou. A maior parte dos registros referese à Feira de Ciências de São Paulo, realizada entre 1960 e 1976, que obteve cobertura da imprensa e consta na literatura sobre a história do ensino de ciências no país como uma importante etapa nas ações do IBECC e na implementação de um ensino mais prático e experimental (MANCUSO; LEITE FILHO, 2006; ABRANTES, 2008). Esse primeiro resultado indica que as matérias sobre as feiras de ciências realizadas no período constituem uma importante fonte de pesquisa para se compreender materiais, métodos, objetivos e demais elementos do ensino de ciências durante as décadas de 1960 e 1970.

Os registros encontrados de trabalhos com animais apresentados nas feiras de ciências de São Paulo durante a década de 1960 mostram que os trabalhos costumavam chamar a atenção do público visitante das feiras. Em alguns registros, os jornais apresentam os trabalhos de "dissecação de animais" como os grandes atrativos das feiras, como nos exemplos da I Feira de São Paulo, em 1960 (FEIRA..., 1960, p.6), e das feiras de Descalvado, em 1964 (A II..., 1964, p.2), e Santo André, em 1967 (SANTO..., 1967, p.2), no interior de São Paulo.

Nesses mesmos registros da década de 1960, os jornais justificam a existência dessas práticas como parte do fazer ciência e do aprender ciência. É possível observar, nesse sentido, que os jornais tendiam a concordar com os princípios e os novos métodos defendidos pelos professores engajados no movimento de renovação do ensino de ciências. 
Em 1962, por exemplo, uma matéria sobre a III Feira de São Paulo iniciou com a descrição da seguinte cena:

"Sinto muito ter de sacrificar este coelho, mas sem ele meu trabalho seria impossível". Era como um menino de curso primário, com apenas 8 anos, iniciava suas demonstrações de História Natural, ante os olhos curiosos de outras crianças e quase espantados dos adultos. (FEIRA..., 1962, p.10)

Neste exemplo, pela primeira vez é possível notar a presença da prática de vivissecção em uma feira, embora não tenha recebido esse nome. Também chama a atenção o "espanto" dos adultos presentes com a prática realizada por uma criança. Vale notar que o jornalista escolheu apresentar, por meio da fala do estudante, a existência de uma preocupação com a morte do animal. A palavra "sacrifício" também é importante nesse contexto, pois ela remete à noção da ciência como um fim maior que justifica essas mortes.

Em 1966, outro exemplo de vivissecção é narrado na sexta edição da Feira de Ciências de São Paulo, salientando o interesse que a prática gerou entre os estudantes:

Num estande mais adiante, [...] parece haver confusão: está na hora de abrir um sapo para mostrar o batimento do coração. Uma vintena de estudantes cercam três alunos atarefados na abertura do quarto sapo (INSTALADA..., 1966, p.7).

Outro texto menciona o mesmo trabalho:

Para mostrar as batidas do coração de um sapo, a cada hora um deles é dissecado ${ }^{8} \mathrm{e}$ para amenizar seu sofrimento - a bem da ciência - o bicho é devidamente anestesiado com éter. Pombos, minhocas e cobras têm o mesmo destino e os cientistas agem com grande naturalidade e competência (PRÊMIOS..., 1966, p.19).

A anestesia dada "para amenizar o sofrimento" dos animais demonstra a preocupação dos jovens com o "sofrimento animal" e a ideia de que eles serviriam ao "bem da ciência" apresenta novamente a noção da necessidade da prática para o avanço científico.

O texto ainda apresenta os jovens expositores como "cientistas" que "agem com naturalidade e competência". Como salientado por Magalhães, Massarani e Norberto Rocha (2019), muitos jornais da época apoiaram a realização das feiras de ciências e realizaram uma cobertura entusiasmada com o potencial que elas poderiam ter para a formação científica dos jovens e para o seu engajamento em carreiras científicas necessárias ao desenvolvimento nacional. Uma forma de visualizar esse entusiasmo e a importância que os jornais atribuíam ao movimento das feiras de ciências que ajudaram a construir com seu apoio e cobertura é observar a maneira como retrataram os estudantes como cientistas em formação ou em miniatura. $\mathrm{Na}$ maior parte das matérias levantadas, o fato de crianças aplicarem métodos científicos, demonstrando seus trabalhos em uma feira de ciências, é sinal de "criatividade", "inteligência", "talento", "vocação científica", entre

\footnotetext{
${ }^{8}$ Neste caso, a matéria se refere à vivissecção, dado que os sapos seriam dissecados ainda vivos.
} 
outros termos elogiosos aos "mini-cientistas" ou "cientistas de amanhã". Essa imagem era acompanhada dos estereótipos e expectativas que se tinha com relação à ciência, ao cientista e à educação científica na época. Nesse exemplo, a naturalidade e a competência diante do sacrifício de um animal apontam tanto para a "frieza" que costuma pesar sobre a imagem do cientista quanto para o domínio das técnicas que se espera da ciência. O fato de jovens estudantes dominarem essas técnicas, nesse contexto, servia como prova de sua "vocação científica" e maturidade para os grandes papéis que estariam destinados a cumprir no progresso do país como futuros cientistas.

Nosso levantamento permitiu observar outros usos de animais no ensino de ciências que escapam aos termos “dissecação de animais" e "vivissecção". Na Feira de São Paulo de 1968, por exemplo, o jornal Folha de São Paulo noticiou o experimento "de psicologia animal" de um grupo de estudantes que teria demonstrado "os efeitos do álcool no comportamento de um galo, provando que ele, embriagado, pode até assumir uma das funções da galinha e chocar ovos" (VEJA..., 1968, p.8). O texto ainda registrou que os jovens, no "quintal da casa de um deles, criam aves, ratos, peixes, aranhas, cachorro e, nos últimos três anos, já fizeram mais de 20 experiências de condicionamento desses animais" (VEJA..., 1968, p.8). O jornal O Estado de São Paulo noticiou a mesma experiência em termos parecidos (FEIRA..., 1968, p.13). Os resultados não são acompanhados de nenhum comentário, mas é possível perceber uma clara aceitação da eficácia desse tipo de pesquisa em oferecer resultados cientificamente interessantes.

O trabalho vencedor da Feira de Ciências de São Paulo de 1969 é um caso que chama bastante a atenção. Intitulado "Observações sobre o comportamento das aranhas sob a ação das toxinas", o trabalho de alunos de Sorocaba apresentou, segundo o jornal O Estado de São Paulo:

aranhas tratadas com entorpecentes (pervitin ${ }^{9}$, benzedrina ${ }^{10}$, cafeína, nicotina e maconha conseguida junto à polícia), que perdiam a noção das coisas e ficavam loucas, fazendo teias sem parar, mesmo dormindo, mas teias irregulares, fora da simetria natural a esses insetos (sic) (ARANHA..., 1969, p.26).

Nota-se que a realização de uma pesquisa com medicamentos e com drogas psicotrópicas ilegais conseguidas pelos alunos na delegacia de polícia são apresentadas pelos jornalistas com naturalidade, ao contrário do que poderia se supor. Além disso, é possível notar que o experimento com “a aranha alucinada pela ação de drogas", que teria "despertado a atenção geral e da própria comissão julgadora" (ARANHA..., 1969, p.26), é apresentado em termos morais extensíveis aos

\footnotetext{
${ }^{9}$ Medicamento com metanfetamina, utilizado como estimulante; foi muito usado pelas tropas nazistas na Segunda Guerra Mundial.

${ }^{10}$ Medicamento com anfetamina, utilizado como estimulante; foi bastante usado pelas tropas americanas na guerra do Vietnã e pelos Beatniks.
} 
humanos - o uso de drogas provocaria a "perda de noção", a "loucura" e a "irregularidade" no comportamento.

A partir de 1970, observa-se uma mudança no padrão das matérias que mencionam experimentos com animais nas feiras de ciências de São Paulo. Na edição daquele ano da Feira de São Paulo, encontramos um registro do jornal $O$ Fluminense, de Niterói-RJ, anunciando que na X Feira poderiam "ser exibidos animais vivos, para o que será necessária licença da Sociedade Protetora dos Animais, não sendo, porém, permitidas experiências de vivissecção" (SÃO..., 1970, p.12). O registro é importante, pois apresenta a atuação de uma organização de proteção aos animais junto às feiras como um órgão regulador dos trabalhos apresentados pelos jovens estudantes e a condenação explícita da prática de vivissecção.

Durante a realização da mesma edição da Feira, um trabalho com animais foi manchete. Segundo o Jornal do Brasil, "um foguete, com rato a bordo" seria "lançado a 300 metros, de meia em meia hora, hoje e amanhã" (FOGUETE..., 1970, p.14). A matéria não especifica o objetivo do experimento, nem comenta a presença do rato, apenas o apresenta como o experimento mais curioso a ser visto no evento. A matéria citada leva a crer que o experimento com o rato obteve a licença junto à organização protetora dos animais.

Dois anos depois, há o registro de uma matéria de 1972, publicada na Folhinha, suplemento infantil da Folha de São Paulo, escrita pela socióloga e educadora Maria Julieta Ormastroni, diretora-executiva do IBECC e diretamente responsável pela organização das feiras de ciências e outros concursos de ciências destinados aos jovens estudantes. Na matéria, a última de uma série publicada por Ormastroni sobre como organizar uma feira, a autora descreveu alguns dos "cuidados indispensáveis para organizar uma feira de ciências do nível primário" (ORMASTRONI, 1972, p.7). Entre os cuidados, é possível ler sobre a importância de "evitar" a "dissecação de animais" (ORMASTRONI, 1972, p.7).

No entanto, na Feira de São Paulo de 1972, o trabalho vencedor, sobre a esquistossomose, teve como uma das principais atrações "um camundongo morto, infestado com a doença e vários cartazes que explicavam a transmissão da doença, seu desenvolvimento e sua prevenção" (SEU..., 1972, p.11). O trabalho e sua autora - uma jovem de 17 anos, estudante de um colégio público de São Paulo, que desejava cursar Medicina - foram tema de uma matéria na Folha de São Paulo (SEU..., 1972, p.11). Entrevistada, a autora explicou que recebeu orientações para o trabalho no setor de Parasitologia da Faculdade de Medicina da USP. O formato do trabalho é tratado na 
matéria com naturalidade e a dissecação do camundongo como uma forma eficaz de ilustrar um problema de saúde pública importante no período.

Na Feira de 1973, alunos com um trabalho sobre injeção de testosterona em pintos (machos) como acelerador na produção agroindustrial de frangos levaram os 15 filhotes submetidos à experiência à Feira (S. PAULO..., 1973, p.17). Em matéria publicada na Folha de São Paulo, os estudantes contaram que receberam "a orientação e a autorização da Sociedade Protetora dos Animais, que indicou a maneira certa de tratar dos bichinhos, sem machucá-los" (ESTUDANTES..., 1973, p.25). A presença deste registro indica que a entidade seguiu atuando como órgão regulador e orientador das maneiras consideradas "certas" de tratamento dos animais levados às edições da Feira de Ciências.

É possível constatar, entre outros aspectos, a existência de uma progressiva alteração da percepção sobre a questão da experimentação com animais nas feiras de ciências e a presença, ao menos a partir da edição 1970, de uma organização de proteção dos animais. A partir de 1974, não foram encontrados mais registros de experimentos com animais em feiras de ciências. A razão disso pode estar nos debates públicos iniciados em 1973 com o Projeto de Lei (PL) 1507 no Congresso Nacional e na mudança de legislação sobre o ensino experimental de ciências no estado de São Paulo nos anos de 1975 e 1976.

\section{O debate público e a proibição da vivissecção e dissecção de animais no ensino de ciências em São Paulo}

O levantamento realizado permitiu mapear a presença nos jornais de uma controvérsia na década de 1970 em torno dos experimentos com animais no ensino básico.

Em 1973, sob pressões dos grupos organizados em torno da "causa animal", como a União Protetora dos Animais (UIPA), a Sociedade União Infantil Protetora dos Animais (SUIPA) e a Sociedade Zoófila Educativa (SOZED), foi apresentado pelo deputado federal Peixoto Filho (MDB) o PL 1507 visando estabelecer normas para a prática didático-científica da dissecção e vivissecção de animais ${ }^{11}$ (PAULINO, 2008). Com a justificativa de que havia "crueldade contra os animais" no ensino e pesquisa científica e que a quantidade de animais mortos para estes fins seria exagerada, o autor do Projeto exigia que as práticas fossem feitas com a supervisão de técnico especializado, com a aplicação de anestesia (no caso da vivissecção) para redução do sofrimento do animal e que o

11 Disponível em: <https://www.camara.leg.br/proposicoesWeb/fichadetramitacao?idProposicao $=192983>$ Acesso em: 22 jun. 2020 
sacrifício do mesmo fosse restringido a casos estritamente necessários. Ao apresentar o Projeto na Câmara Federal, o deputado leu a carta de uma mãe que denunciava a prática da vivissecção na escola dos filhos ${ }^{12}$. Segundo a carta, a prática seria cruel, traumatizante e poderia desenvolver nas crianças a insensibilidade, o desrespeito à "lei da vida" e a "curiosidade mórbida".

Nos meses anteriores à apresentação do PL, algumas matérias foram veiculadas em diferentes jornais denunciando o sofrimento dos animais submetidos às pesquisas científicas e às experiências nas aulas de ciências. Em janeiro de 1972, o jornal O Estado de São Paulo publicou o texto Em nome da ciência, animais morrem (1972, p.36). Segundo a matéria, o tema seria alvo de denúncia há anos por parte da UIPA. Entre outras questões, o jornal abordou o uso de animais no ensino básico:

Nos colégios brasileiros, os sapos são as maiores vítimas. São dissecados vivos, quase nunca anestesiados, e a experiência chega a ser a grande atração de feiras de ciências: os sapos são cortados, diante de um público apenas curioso, por ginasianos que desconhecem as técnicas mais elementares, dêsse trabalho (EM NOME..., 1972, p.36).

Segundo um representante da UIPA, entrevistado pelo jornal, "nos colégios, o animal é praticamente picado em pedaços e sempre termina sacrificado" (EM NOME..., 1972, p.36). O exagero das imagens acompanha as descrições ao longo da maior parte dos registros de opiniões contrárias ao uso de animais levantados.

O jornal entrevistou também dois professores de ciências de Sorocaba. O primeiro defendeu a vivissecção no ensino básico, se realizada com os "métodos corretos" e "os modernos processos de anestesia", afirmando que "nenhum boneco pode substituir o modelo vivo no ensino da físiologia" (EM NOME..., 1972, p.36). O outro professor - segundo a matéria um dos iniciadores das feiras de ciências na cidade do interior de São Paulo, "onde uma das grandes atrações era precisamente a vivissecção de animais feita por ginasianos" - teria se posicionado contrário à utilização de sapos, recorrendo a argumentos utilitários e "ecológicos". Segundo ele, os sapos "são animais úteis e seu extermínio provoca sempre um aumento do número de insetos nocivos [...]. As experiências devem utilizar apenas animais criados para essa finalidade, como os ratos brancos, que não têm qualquer utilidade na natureza" (EM NOME..., 1972, p.36).

No ano seguinte, o Jornal do Brasil descreveu o uso de animais em experiências científicas como "tortura cientifica" em texto intitulado Matar para experimentar (1973, p.1). No mesmo período, uma grande matéria escrita pelo poeta e jornalista Álvaro Alves de Faria foi reproduzida em dois jornais diferentes (Correio Braziliense, do Distrito Federal, e Diário da Noite, de São

12 Disponível em: <http://imagem.camara.gov.br/Imagem/d/pdf/DCD06MAR1974.pdf\#page=37> Acesso em 10 out. 2020 
Paulo) com a mesma manchete: A ciência da crueldade (FARIA, 1973a, p.6; 1973b, p.5). No texto, Faria demandou a regulamentação do "uso indiscriminado da vivissecção" (FARIA, 1973a, p.6; 1973b, p.5). É interessante notar que parte do conteúdo da matéria de Faria foi reproduzido integralmente por Peixoto Filho na justificativa de seu PL, um indício de que os jornais da época tiveram um papel importante no desenvolvimento da questão. Uma matéria do Estado de São Paulo confirma essa suspeita ao registrar que o deputado "baseou-se em denúncias de jornais" para formular sua proposta (LEI..., 1976, 14).

Ainda em 1973, outros dois deputados teriam se manifestado contra as práticas nas escolas brasileiras. Primeiro, o deputado paulista Faria Lima (ARENA) levantou a questão na Câmara, citando a "numerosa correspondência" com denúncias de pais de que crianças de oito a 14 anos estariam ficando "traumatizadas ao ver ratinhos serem autopsiados nas salas de aulas para, em seguida, serem jogados na cesta do lixo da sala de aula" (PASSARINHO..., 1973, p.10). Lima defendeu uma ampla investigação nas escolas que, segundo ele:

[...] a título de ensino de Ciências, traumatizam seus alunos, dissecam animais em cerimônias macabras e que não surtem nenhum efeito senão o de causar repugnância às crianças, tirar-lhes o apetite e até provocar nelas aversão pelos animais (PASSARINHO..., 1973, p.10).

Em dezembro de 1973, o então ministro da educação Jarbas Passarinho acatou o pedido do deputado e, segundo o Jornal do Brasil, "mandou investigar junto às Secretarias de Educação dos Estados, quais estabelecimentos de ensino que dissecam pequenos animais, sem base científica" (PASSARINHO..., 1973, p.10). Não foi possível averiguar o resultado dessa investigação.

Em seguida, o deputado José Camargo (MDB), também de São Paulo, teria discursado na Câmara de deputados em Brasília contra a vivissecção no ensino básico. Segundo o jornal $O$ Estado de São Paulo, o deputado teria mencionado "várias cartas de professoras de escolas públicas do Estado de São Paulo" que "denunciaram a inclusão de práticas de vivissecção de cães, gatos e coelhos nas aulas de estudos de fenômenos fisiológicos" (DEPUTADO..., 1973, p.37). Camargo teria dito ainda que "os pais não aprovam este tipo de ensino" capaz, segundo ele, de formar "verdadeiros Frankensteins, pois, como observa uma das professoras que me escreveu, tais aulas resultam no embrutecimento das crianças, tirando-lhes, inclusive, a sensibilidade e o amor" (DEPUTADO..., 1973, p.37). O jornal ainda ouviu o médico Paulo Tavares, professor de Medicina Experimental da Universidade de Brasília. Tavares teria dito que "jamais assistiu, no Brasil, a uma experiência com fins didáticos em que o animal não tenha sido devidamente tratado" e que o importante não seria tornar a prática ilegal, mas garantir que "os animais não podem sofrer, devem ser bem alimentados e guardados em locais adequados" (DEPUTADO..., 1973, p.37). 
A mídia e a experimentação com animais no ensino básico de ciências no estado de São Paulo: uma análise da cobertura feita por jornais impressos nas décadas de 1960 e 1970

No ano de 1974, encontramos um registro noticiando que a UIPA teria se manifestado, segundo a Folha de São Paulo, contra "a prática indiscriminada da vivissecção em diversas 'Feiras de Ciências', onde crianças de até 12 anos de cursos primários estão abrindo animais”, depois que “inúmeros protestos" chegaram à sede da UIPA, "enviados por pais de alunos" (UNIÃO..., 1974, p.7). A entidade teria enviado um ofício ao Ministério da Educação solicitando providências, uma vez que, para a UIPA, trataria-se de "um perigoso precedente para um desajuste emocional futuro. De sapos, coelhos, cobaias e cães, essas crianças passarão a tratar os homens com a mesma indiferença e instintivamente chegarão à crueldade" (UNIÃO..., 1974, p.7). Neste exemplo, o estereótipo da ciência como um campo racional, frio e indiferente é utilizado para denunciar as práticas com animais como um perigo à formação moral dos jovens. Segundo a UIPA, o código penal já previa penas para "aquele que, embora para fins didáticos ou científicos, realiza em lugar público ou exposto ao público experiência cruel e dolorosa em animal vivo". A entidade teria sugerido que os animais vivos fossem "substituídos por filmes ou modelos de plástico, conforme os usados na Inglaterra e outros países" (UNIÃO..., 1974, p.7).

Em nosso levantamento, identificamos 28 cartas de leitores que se manifestaram sobre o tema e foram publicadas pelos jornais entre 1973 e 1979. Entendemos que elas manifestam a intenção dos jornais de construir uma aparência de debate com engajamento público e uma adesão da opinião pública a uma posição no interior desse debate. Todas elas se posicionam contra a "vivissecção", apresentando-a como "traumatizante" para as crianças, que cresceriam "embrutecidas" e "sádicas". A maior parte das cartas teria sido enviada por pais de alunos. Uma delas é de uma aluna que seria contra a prática da vivissecção, mesmo ela não existindo em sua escola. Há também a carta de uma professora, que não menciona a prática no estabelecimento de ensino onde trabalha, mas diz que decidiu se manifestar contra a prática depois de ler sobre o assunto nos jornais.

Em 1975, o Senador Benjamin Farah (MDB) propôs o PL no 104 ao Senado Federal igualmente proibindo a vivissecção de animais em estabelecimentos de ensino de $1^{\circ}$ e $2^{\circ}$ graus. O projeto apontou para o "falacioso pretexto de que se trata de "preparação vocacional" de "pseudocientistas" que "não passam de adolescentes inteiramente despreparados para um comportamento dessa ordem" (BRASIL, 1976, p.193). Em setembro de 1975, na Câmara de Deputados do estado de São Paulo, o deputado estadual Francisco Antônio Coelho (MDB) apresentou o PL 389 com a proposta de proibição das práticas no ensino básico paulistano.

No mesmo ano, 1975, encontramos os registros de um intenso debate sobre as práticas de dissecção e vivissecção no ensino de ciências. O Estado de São Paulo chegou a registrar que a 
controvérsia dividia "professores, cientistas e naturalistas" em dois lados, com acusações mútuas de "bárbaros" e "obscurantistas" (EGYDIO..., 1976, p.22). Primeiro, o Ministério da Educação teria enviado um ofício ao Conselho Estadual de Educação de São Paulo (CEE-SP) - órgão normativo, deliberativo e consultivo do sistema educacional público e privado paulista criado em $1963^{13}$ propondo um debate sobre o uso de animais no ensino de ciências, sugerindo a tomada de uma posição oficial e insinuando que essa posição deveria ser a de evitar tais práticas nas escolas (ABRAMO, 1975). No mesmo período, o PL 1507, primeira proposta de regulamentação, como apresentado acima, já estava tramitando na esfera federal.

O sociólogo e jornalista Perseu Abramo registrou a questão em sua coluna Educação na Folha de São Paulo. Segundo Abramo, no documento, o Ministério teria alegado "ter tomado conhecimento, por cartas e pelos jornais, de 'inúmeras manifestações, ora de repúdio, ora de apreensão, face ao uso indiscriminado e constante da técnica de vivissecção no ensino de Ciências (ABRAMO, 1975, p.25). Abramo ainda registrou a forma como a polêmica estava pautada:

Os que se colocam contra a prática de experiências desse tipo com animais nas escolas de primeiro e segundo graus são movidos por diversas razões: o sentimento de piedade para com os animais, as preocupações com o equilíbrio ecológico, o temor de que as crianças sejam induzidas a atos de perversidade, a consideração da ineficácia pedagógica do método, a aversão íntima pela manipulação de organismos animais, e muitas outras.

Os que defendem essas experiências argumentam, também, de diversos modos: a necessidade de substituir o conhecimento livresco e palavroso pelo experimento concreto, a conveniência de induzir as crianças ao respeito pelos princípios fundamentais do método científico, a consideração de que vale mais a educação das crianças do que uma pretensa caridade para com os animais (ABRAMO, 1975, p.25).

Abramo registrou também um ponto importante: tomando-se a realidade brasileira e, especificamente, a paulistana, seria necessário considerar as grandes desigualdades existentes nas escolas. "Na imensa maioria das escolas não há nem a preocupação nem as condições para que o ensino de ciências não seja feito da forma tradicional”, registrou o sociólogo e jornalista (ABRAMO, 1975, p.25). Além disso, escreveu, "há também que ponderar a heterogeneidade do alunado [...]: existem diferenças de sensibilidade e de capacidade crítica" que deveriam ser consideradas (ABRAMO, 1975, p.25). Por fim, Abramo sugeriu que o CEE-SP evitasse "uma posição absoluta e inflexível de proibição ou permissão", mas sim que chegasse a um meio termo de regulamentação das experiências (ABRAMO, 1975, p.25).

No mesmo ano, o CEE-SP reuniu-se para debater a "dissecação e a vivissecção de animais em aulas de Ciências no $1^{\circ}$ e $2^{\circ}$ graus" (AS... , 1975, p.13). O jornal Folha de São Paulo registrou que,

\footnotetext{
${ }^{13}$ Disponível em: <http://www.ceesp.sp.gov.br/> Acesso em: 05 out. 2020.
} 
A mídia e a experimentação com animais no ensino básico de ciências no estado de São Paulo: uma análise da cobertura feita por jornais impressos nas décadas de 1960 e 1970

em maio daquele ano, "após uma série de protestos de pais e entidades [...] as experiências de dissecção e vivissecção sofreram em maio uma regulamentação restritiva por parte da Secretaria de Educação (AS ..., 1975, p.13). Em comunicado aos diretores das Divisões Regionais de Educação, a Secretaria teria proibido "entre outras coisas, a utilização de animais 'que defendam a vida do homem ou lhe prestem serviços, tais como cães, gatos, jumentos e outros em atividades desse tipo" (AS..., 1975, p.13). Além disso, o comunicado "limitava exclusivamente às duas últimas séries do $1^{\circ}$ grau e às classes de $2^{\circ}$ grau 'cujos alunos já se encontram amadurecidos"” e determinava que os animais fossem apresentados já mortos aos alunos (AS ..., 1975, p.13).

A matéria registrou ainda que a conselheira Rachel Gevertz (educadora, ligada ao IBECC e ao movimento renovador, e, posteriormente, ao projeto Estação Ciência ${ }^{14}$ ) teria escrito um parecer apresentando "possíveis razões e objetivos pedagógicos que poderiam justificar a manutenção de experiências com animais no ensino de Ciências nos $1^{\circ}$ e $2^{\circ}$ graus" (AS..., 1975, p.13). No entanto, Gevertz concluiu o parecer se mostrando favorável à "abolição" da prática e à implementação de "uma série de atividades substitutivas" (AS..., 1975, p.13). É interessante notar que, em um item específico do relatório, Gevertz teria defendido a proibição definitiva "das dissecações e vivissecções de animais, e de outros experimentos dolorosos ou cruéis realizados em Feiras de Ciências, ou outras demonstrações públicas” (DISSECAÇÃO..., 1975, p.20).

O parecer de Gevertz foi considerado "muito drástico" e a decisão foi adiada (DISSECAÇÃO..., 1975, p.20). O padre Lionel Corbeil, membro-fundador do CEE-SP, considerou que a questão dependia de "um estudo mais aprofundado", pois acreditava que os alunos do $2^{\circ}$ grau "deveriam estar em contato com dissecação de animais durante as aulas", atividade capaz de “enriquecer sua vocação" (DISSECAÇÃO..., 1975, p.20). Corbeil, então, teria dito que formaria "uma equipe de trabalho, com a participação de um professor de Biologia, com o objetivo de executar um novo parecer, ou reformular o atual” (DISSECAÇÃO..., 1975a, p.20). O jornal Folha de São Paulo deu destaque para o debate, estampando a manchete Dissecação e vivissecção em questão na capa (1975, p.1). A chamada da matéria registrou uma oposição polarizada sobre o assunto:

A vivissecção, sobretudo, mas também a dissecação, são combatidas por pessoas e instituições ligadas à proteção dos animais. A maioria dos professores, entretanto, alega o interesse científico dessas práticas e gostaria de as manter em seu ensino (DISSECAÇÃO..., 1975b, p.1).

14 Disponível em: <http://www.apedu.org.br/site/2011/05/11/discurso-de-saudacao-a-academica-rachel-gevertz/> Acesso em 12 out. 2020 
Em outra matéria, do mesmo período, no entanto, é possível ler que os "professores estão divididos", seguido do relato de cinco professores com posições muito distintas (EXPERIÊNCIAS..., 1975b, p.19).

Em outubro de 1975, a Folha de São Paulo registrou a campanha pela proibição da vivissecção no ensino de ciências nos dois graus realizada pela SOZED. O objetivo da instituição seria "defender a integridade moral das nossas crianças e jovens e evitar o morticínio cruel e desnecessário de milhares de animais" (SOCIEDADE..., 1975, p.38). O principal argumento da SOZED teria sido "o risco de, mediante tais práticas, incentivar nas crianças e jovens uma curiosidade mórbida e uma frieza maléfica" (SOCIEDADE..., 1975, p.38). Consultado sobre o assunto, o professor Paulo Sawaya (titular em Fisiologia Geral e Animal do Instituto de Biociências da USP, ligado ao IBECC) expressou sua opinião de que "a vivissecção não deve jamais ser apresentada às crianças e adolescentes, por provocar traumatismo de tal ordem que leva a um conceito errôneo do que venha a ser o método experimental" (SOCIEDADE..., 1975, p.38).

No final de 1975, o padre Corbeil apresentou o parecer com a intenção de restringir as práticas de dissecção e vivissecção animal no ensino de ciências. Ao introduzir o assunto, Corbeil salientou o papel da imprensa, que "chamou a atenção do público sobre o assunto" (CONSELHO..., 1975, p.16). Note-se que parte importante do papel da imprensa na publicização das referidas práticas no ensino de ciências refere-se, em parte, às matérias sobre feiras de ciências, com importante presença nos jornais nas décadas de 1960 e 1970, como observado anteriormente.

Com a justificativa de que a "sua aplicação indiscriminada pode acarretar abusos de graves consequências para sua educação, podendo até provocar traumatismos, ao mesmo tempo que ofenderia a dignidade do reino animal”, o parecer indicou a proibição das práticas, com exceção para aos cursos profissionalizantes (CONSELHO ..., 1975, p.16).

O parecer informou ter havido uma consulta a três instituições de defesa e promoção da ciência e do ensino de ciências: a Sociedade Brasileira para o Progresso da Ciência (SBPC), o Centro de Treinamento para Professores de Ciências de São Paulo (CECISP) e a Fundação Brasileira para o Desenvolvimento do Ensino de Ciências (FUNBEC). As três fizeram uma defesa intransigente do ensino prático e experimental. A SBPC teria se posicionado contra a restrição das práticas, considerando que "quando realizadas dentro dos padrões de ética profissional, não produzem os efeitos traumatizantes que são levianamente aventados; é de se julgar que a proibição das mesmas, além de ser uma atitude obscurantista, faria recuar o ensino de ciências a um nível puramente teórico" (CONSELHO..., 1975, p.16). O posicionamento do CECISP, redigido pela professora Myriam 
A mídia e a experimentação com animais no ensino básico de ciências no estado de São Paulo: uma análise da cobertura feita por jornais impressos nas décadas de 1960 e 1970

Krasilchik (outra figura importante no movimento de renovação do ensino de ciências), considerou que o "ensino de Ciências deve incluir o trabalho com organismos vivos para que os alunos compreendam a natureza dos processos biológicos" e que "a proibição indiscriminada de dissecções ou mesmo sua restrição a cursos profissionalizantes será prejudicial ao ensino de Ciências e ferirá a autonomia das escolas" (CONSELHO..., 1975, p.16). Já a FUNBEC afirmou que:

[...] deve-se exigir que, em Ciências Naturais, as descobertas sejam feitas, na medida do possível, pelo aluno, durante uma experimentação pessoal. [...] impedir a realização de atividades práticas de vivissecção e dissecação apenas agravaria o problema do ensino de Ciências Naturais. [...] parece-nos que antes da proibição, na verdade o que se faz necessário são medidas concretas de esclarecimento aos professores, às autoridades de ensino e ao público em geral (CONSELHO..., 1975, p.16).

Por fim, após "vivos debates", o CEE-SP deliberou, em novembro de 1975, por recomendar que as experiências fossem realizadas apenas no segundo grau, sob responsabilidade do professor, que deveria ser treinado para a aplicação dos métodos (EXPERIÊNCIAS..., 1975a, p.20).

No ano seguinte, a UIPA continuou fazendo campanha contra as práticas de dissecção e vivissecção, especialmente nas escolas, como noticiou a Folha de São Paulo (CONTRA..., 1976, p.27).

Em 21 de outubro de 1976, foi sancionada a Lei 1.122 no estado de São Paulo proibindo as práticas de "dissecção e vivissecção de animais em laboratório de estabelecimentos de ensino de $1 .^{\circ}$ Grau" em todo o estado de São Paulo. No segundo grau, as experiências foram reguladas. Segundo o jornal $O$ Estado de São Paulo, a medida foi a primeira a restringir as práticas no ensino básico no Brasil (EGYDIO..., 1976, p.22). Não sabemos os efeitos práticos do debate, da recomendação do CEE-SP e da Lei 1.122, mas, como dito anteriormente, nas buscas realizadas na Hemeroteca Digital e nos acervos de outros jornais não foram encontrados registros de experiências com animais nas feiras de ciências a partir do ano 1974, o que sugere uma alteração no ensino concomitante ao debate público.

Em 1979, foi aprovada a Lei 6638, uma fusão dos projetos que tramitavam na Câmara e no Senado Federal, que regulamentou a prática didático-científica com animais e proibiu a vivissecção "em estabelecimentos de ensino de primeiro e segundo graus e em quaisquer locais frequentados por menores de idade" em todo o território nacional (PAULINO, 2008). Para Guimarães et al., (2016), a Lei nunca teria recebido a devida normatização, de modo que não houve atribuição legal de órgão competente, que seria responsável por zelar pelo cumprimento de suas normas e cadastramento das instituições e profissionais dedicados ao uso e à criação de animais com 
finalidade didático-científica. Para ativistas contrários à experimentação, a Lei 6638 teria tido o efeito insuficiente de apenas regularizar as práticas no ensino (PAULINO, 2008).

$\mathrm{Na}$ literatura consultada sobre a história do ensino de ciências e a história do uso de animais em experimentações didático-científicas no Brasil, não foram encontradas menções a este debate ocorrido em 1975 e 1976 no contexto paulistano, tampouco à Lei 1.122 de 1976 no estado de São Paulo. A maior parte dos trabalhos foca nos debates na esfera federal em torno da Lei 6638 de 1979 e da Lei Arouca de 2008 (cf. PAULINO, 2008; RAMIRO, 2011). Esta aparente ausência nos leva a crer que o debate ocorrido em 1975 e 1976 e as possíveis relações com o movimento de renovação do ensino de ciências e, particularmente, com as feiras de ciências é algo ainda inexplorado.

\section{Considerações Finais}

A partir da exploração e análise dos 109 registros jornalísticos levantados na Hemeroteca Digital e nos acervos digitais dos jornais $O$ Globo, Folha de São Paulo e O Estado de São Paulo entre as décadas de 1950 e 1970, observamos que os registros de usos de animais no ensino de ciências são todos de trabalhos apresentados nas feiras de ciências organizadas nas décadas de 1960 e 1970 pelos promotores da renovação do ensino de ciências. Foi possível constatar, nesses eventos, a presença das práticas de dissecção e vivissecção, como as incentivadas pelos livros didáticos e que foram, posteriormente, objetos de regulamentações na segunda metade da década de 1970. Foi possível também observar outros métodos, como a injeção de hormônios ou de drogas psicoativas e experimentos sobre comportamento animal, que não foram alvo de polêmica.

Nos primeiros anos da década de 1960, os registros jornalísticos de usos de animais em experimentos no ensino básico apontaram para a maneira como os jornais apresentaram os possíveis riscos e sofrimentos implicados na pesquisa como parte do aprendizado do fazer ciência. É possível observar uma concordância dos jornais com os princípios e novos métodos defendidos pelos professores engajados no movimento de renovação. Já na virada para a década de 1970, foi possível constatar algumas modificações importantes, inclusive não sendo recomendada pela organização da Feira de São Paulo, em texto publicado por sua coordenadora. Notamos a condenação às práticas de dissecção e vivissecção e a presença de entidades de proteção animal atuando como reguladoras das práticas com animais no ensino alguns anos antes que os debates sobre o assunto tivessem repercussão nacional em 1973.

Ao analisar a presença nos jornais da controvérsia que se estabeleceu no país a partir de 1973 e que resultou na Lei estadual de 1976 em São Paulo e na Lei federal de 1979, observamos que os 
jornais veicularam vozes contrárias aos experimentos com animais, vistos como "cruéis" com os animais, desnecessárias, além de potencialmente traumatizantes e desreguladoras de uma formação moral "normal" dos jovens estudantes. Também observamos que as matérias que cobriam as feiras de ciências e descreviam trabalhos com a utilização de animais serviram de base aos críticos das práticas. É importante salientar que um dos argumentos centrais dos que se contrapunham às práticas é o questionamento do caráter científico dos experimentos no ensino básico, mantendo a noção de que o "sacrifício" dos animais seria válido apenas para as pesquisas realizadas por uma ciência praticada por verdadeiros cientistas. Enquanto os jornais costumavam descrever os estudantes como "minicientistas" ou "jovens cientistas", os críticos apontavam os jovens como “pseudocientistas" emocionalmente despreparados para esse tipo de atividade.

Por outro lado, foi possível constatar que os jornais registraram a existência de uma defesa, por parte de alguns educadores e instituições científicas, das práticas de dissecção e vivissecção como parte do repertório dos novos métodos de ensino experimental, mesmo durante a controvérsia, em oposição ao modelo anterior de ensino puramente teórico, combatido pelo movimento renovador da educação. No entanto, não havia consenso sobre o tema, mesmo entre os educadores mais fortemente vinculados ao movimento.

Nosso estudo dá algumas luzes sobre as discussões na esfera pública das controvérsias em torno dos experimentos com animais no ensino básico e, esperamos, pode provocar o surgimento de novas questões que possam servir a estudos futuros.

\section{Agradecimentos}

Este estudo foi realizado no âmbito do Instituto Nacional de Comunicação Pública da Ciência e Tecnologia (INCT-CPCT) e conta com apoio do Conselho Nacional de Desenvolvimento Científico e Tecnológico (CNPq) e da Fundação de Amparo à Pesquisa do Estado do Rio de Janeiro (Faperj). O primeiro autor agradece à Faperj pela bolsa TCT. A segunda autora agradece ao CNPq pela Bolsa Produtividade em Pesquisa 1B e à Faperj pela bolsa de Cientista do Nosso Estado. A terceira autora agradece à FAPERJ pela bolsa de Jovem Cientista do Nosso Estado. Todos os autores agradecem à Hemeroteca Digital da Biblioteca Nacional e ao Instituto de Biologia Roberto Alcantara Gomes (Ibrag) da Universidade do Estado do Rio de Janeiro (UERJ), particularmente à professora Marly Cruz Veiga da Silva e equipe responsável pelo Memorial do Ensino de Ciências da UERJ. 


\section{Referências}

A II Feira de Ciências de Descalvados. Jornal do Commercio: Rio de Janeiro, 30 ago. 1964, p.2.

A CIÊNCIA da crueldade. Diário da Noite: São Paulo, 28 mai. 1973a, p.6.

A CIÊNCIA da crueldade. Correio Braziliense: Brasília, 3 jun. 1973b, p.5

ABRAMO, P. Experiências. Coluna Educação. Folha de São Paulo: São Paulo, 24 ago. 1975, Educação, $3^{\circ}$ caderno, p. 25 .

ABRANTES, A. C. S. de. Ciência, Educação e Sociedade: o caso do Instituto Brasileiro de Educação, Ciência e Cultura (IBECC) e da Fundação Brasileira de Ensino de Ciências (FUNBEC). Tese (Doutorado em História das Ciências e da Saúde) - Fundação Oswaldo Cruz. Rio de Janeiro, 2008.

ARANHA alucinada dá o prêmio a Sorocaba. O Estado de São Paulo: São Paulo, 26 jun. 1969, p.26.

ARAÚJO, J. C.; GATTI JÚNIOR, D. (orgs.). Novos Temas em História da Educação Brasileira: instituições escolares e educação na imprensa. Campinas: Autores Associados; Uberlândia, MG: EDUFU, 2002.

ARNAUT DE TOLEDO, C. A.; SKALINSKI JUNIOR, O. A imprensa periódica como fonte para a história da educação: teoria e método. Revista HISTEDBR On-line, n.48, p. 255-268, dez. 2012.

AS experiências com bichos: hoje, debate. Folha de São Paulo: São Paulo, 20 ago. 1975, p.13.

BARRA, V. M.; LORENZ, K. M. Produção de materiais didáticos de ciências no Brasil, período: 1950 a 1980. Ciência e Cultura, n.38, v.12, 1986, p.1970-1983.

BASTOS, M. H. C. Espelho de papel: a imprensa e a história da educação. In: ARAÚJO, J. C. S.; GATTI JÚNIOR, D. (Orgs.). Novos temas em História da Educação Brasileira: instituições escolares e educação na imprensa. Campinas: Autores Associados; Uberlândia, MG: EDUFU, 2002. p. 151-171.

BIOLOGICAL SCIENCE CURRICULUM STUDY (BSCS). Biologia: das moléculas ao homem, versão azul, vol. I. São Paulo: EDART, 1969.

BIOLOGICAL SCIENCE CURRICULUM STUDY (BSCS). Biologia, versão verde, vol. III. São Paulo: EDART, 1976a.

BIOLOGICAL SCIENCE CURRICULUM STUDY (BSCS). Guia do Professor de Biologia: das moléculas ao homem, versão verde, vol. I. São Paulo: EDART, 1976 b.

BORGES, R. M. R.; IMHOFF, A. L.; BARCELLOS, G. B. (Org.). Educação e cultura científica e tecnológica: centros e museus de ciências no Brasil. Porto Alegre: EDIPUCRS, 2012.

BRASIL. Congresso Nacional. Anais do Senado. Mês de junho de 1975, Sessões $71^{\mathrm{a}}$ a $91^{\mathrm{a}}$. Volume II. Subsecretaria de Anais. Brasília, 1976.

CAMPOS, R. D. de. No rastro de velhos jornais: considerações sobre a utilização da imprensa não pedagógica como fonte para a escrita da história da educação. Revista Brasileira de História da Educação, Campinas, n.12 v.1-28, p.45-70, jan./abr. 2012.

CASSAB, M. O Movimento Renovador do Ensino das Ciências: entre renovar a escola secundária e assegurar o prestígio social da ciência. Revista Tempos e Espaços em Educação, v.8, n.16, p.1935, mai./ago 2015. 
CIÊNCIA vai às ruas para educar o povo. O Estado de São Paulo: São Paulo, 27 mai. 1972, p.12.

CONSELHO deve decidir hoje a dissecação. Folha de São Paulo: São Paulo, 05 nov. 1975, Educação, p.16.

CONTRA a vivissecção. Saber. Folha de São Paulo: São Paulo, 03 abr. 1976, Nova Mulher, p.27.

DISSECAÇÃO de animais nas escolas: decisão é adiada. Folha de São Paulo: São Paulo, 21 ago. 1975a, Educação, p.20.

DISSECAÇÃO e vivissecção em questão. Folha de São Paulo: São Paulo, 1975b, p.1.

EM NOME da ciência os animais morrem. O Estado de São Paulo: São Paulo, 30 jan. 1972, p.36.

EGYDIO proíbe dissecação de animais na rede escolar. O Estado de São Paulo: São Paulo, 22 out. 1976, p.22.

ESTUDANTES e ciência, 3 dias no Ibirapuera. Folha de São Paulo: São Paulo, 25 mai. 1973, Educação, p.25.

EXPERIÊNCIAS ganham recomendações no CE. Folha de São Paulo: São Paulo, 6 nov. 1975a, Educação, p.20.

EXPERIÊNCIAS: proibidas no $1^{\circ}$ grau mas reguladas no $2^{\circ}$. Folha de São Paulo: São Paulo, 11 set. 1975b, Educação, p.19.

FEIRA mostra ciência jovem. O Estado de São Paulo: São Paulo, 25 mai. 1968, p.13.

FEIRA de Ciências. O Estado de São Paulo: São Paulo, 23 abr. 1960, p.12.

FEIRA de ciências: gente miúda trabalhou como gente grande. Folha de São Paulo: São Paulo, 10 out. 1962, Caderno Ilustrada, p.10.

FOGUETE com rato a bordo é lançado a 300m pela Feira de Ciências do Ibirapuera. Jornal do Brasil: Rio de Janeiro, 03 mai. 1970, p.14.

GONÇALVES, F. P. O Texto de Experimentação na Educação em Química: discursos pedagógicos e epistemológicos. Dissertação (Mestrado em Educação Científica e Tecnológica). Programa da Pós-Graduação em Educação Científica e Tecnológica da Universidade Federal de Santa Catarina, Florianópolis, 2005.

GUIMARÃES, M. V.; FREIRE, J. E. Da C.; MENEZES, L. M. B. Utilização de animais em pesquisas: breve revisão da legislação no Brasil. Revista Bioética, v.24, n.2, p.217-224, 2016.

INSTALADA ontem com êxito a VI Feira de Ciências no Pacaembu. Folha de São Paulo: São Paulo, 14 mai. 1966, p.7.

KRASILCHIK, M. Reformas e Realidade: o caso do ensino das ciências. São Paulo em Perspectiva, v.14, n.1, p.85-96, 2000.

LEI proibirá a vivissecção no ensino de ciências. O Estado de São Paulo: São Paulo, 12 mai. 1976, p.14.

LUCA, T. R. de. Fontes impressas: história dos, nos e por meio dos periódicos. In: PINSKY, C. B. (org.). Fontes Históricas. São Paulo: Contexto, 2008.

MAGALHÃES, D. C.; MASSARANI, L.; NORBERTO ROCHA, J. (2019) 50 anos da I Feira Nacional de Ciências (1969) no Brasil. Revista Interfaces Científicas - Humanas e Sociais, v.8, n.2, p.185-202, 2019. 
MANCUSO, R.; LEITE FILHO, I. Feiras de Ciências no Brasil: uma trajetória de quatro décadas. In: BRASIL. Ministério da Educação/ Secretaria de Educação Básica. Programa Nacional de Apoio às Feiras de Ciências da Educação Básica. Brasília: Ministério da Educação/ Secretaria de Educação Básica, 2006.

MASSARANI, L.; JURBERG, C.; MEIS, L. de (org.). Um gesto ameno para acordar o país: a ciência no Jornal do Commercio [1958-1962]. Rio de Janeiro: Fundação Oswaldo Cruz/Casa de Oswaldo Cruz, 2011.

MATAR para experimentar. Jornal do Brasil: Rio de Janeiro, 30 mar. 1973, caderno B, p.1. NORBERTO ROCHA, J.; MAGALHÃES, D. C.; MASSARANI, L.; DAHMOUCHE, M. S. De Cecigua a Cecierj: trajetórias na educação em ciências e na divulgação científica no estado do Rio de Janeiro. Rio de Janeiro: Fundação Cecierj, 2020.

ORMAStroni, M. J. Feira de Ciências ao nível do Primário (fim). Folha de São Paulo: São Paulo, 02 jan. 1972, Caderno Folhinha, p.7.

PASQUINI, A. S.; ARNAUT DE TOLEDO, C. A. Historiografia da Educação: a imprensa enquanto fonte de investigação. Interfaces Científicas - Educação, v.2, n.3, p.257-267, Jun. 2014.

PASSARINHO manda apurar se crianças são traumatizadas com dissecação de animais. Jornal do Brasil: Rio de Janeiro, 3 dez. 1973, p.10.

PAULINO, C. A. A. Conflitos e Interesses acerca do Controle sobre a Experimentação Animal em São Paulo. Dissertação (Mestrado em Antropologia Social). Programa de Pós-Graduação em Antropologia Social, Universidade de Campinas, Campinas, 2008.

PRÊMIOS da VI Feira de Ciências serão distribuídos hoje. Folha de São Paulo: São Paulo, 15 mai. 1966, p.19.

RAMIRO, D. P. Vivissecção: uma disputa em sua regulamentação - das ruas ao parlamento. Dissertação (Mestrado em Antropologia Social). Programa de Pós-Graduação em Antropologia Social, Universidade de Campinas, Campinas, 2011.

S. PAULO mostra trabalhos de jovens cientistas na Grande Feira de Ciências e Cultura. Jornal do Brasil: Rio de Janeiro, 26 mai. 1973, p.17.

SANTO André. A Tribuna: São Paulo, 26 nov. 1967, Litoral e Interior, p.2.

SANTOS, N. D. dos. Práticas de ciências: conteúdo e didática (Guia de Ensino Elementar). Rio de Janeiro: Olímpica, 1968.

SÃO Paulo promove Feira de Ciências. O Fluminense: Niterói, 12 abr. 1970, p.12.

SCHELBAUER, A. R.; ARAÚJO, J. C. (orgs.). História da educação pela imprensa. Campinas: Editora Alínea, 2007.

SEU sonho sempre foi a Medicina. Folha de São Paulo: São Paulo, 30 mai. 1972, Educação, $2^{\circ}$ Caderno, p.11.

SILVA, B. C. Breve História do Cecine: a verdade científica virou dúvida e experimentação. In: BORGES, R. M. R.; IMHOFF, A. L.; BARCELlOS, G. B. Educação e Cultura Científica e Tecnológica: centros e museus de ciências no Brasil. Porto Alegre: EDIPUCRS, 2015.

SILVA, T. R. da. "Um Curso Moderno de Biologia para a Escola Secundária" (1965-1972): as configurações do currículo do BSCS versão azul no Brasil. Revista Humanidades e Inovação, v.7, n.8, p.125-140, 2020. 
SOCIEDADE quer o fim da vivissecção. Folha de São Paulo: São Paulo, 5 out. 1975, Educação, $3^{\circ}$ caderno, p.38.

UNIÃO critica vivissecção. Folha de São Paulo: São Paulo, 27 jun. 1974, Local, p.7.

VALLA, D. F.; ROQUETTE, D. A. G.; GOMES, M. M.; FERREIRA, M. S. Disciplina escolar Ciências: inovações curriculares nos anos de 1950-1970. Ciência \& Educação (Bauru), v.20, n.2, p.377-391, 2014.

VEJA o que os jovens cientistas de S. Paulo fazem em Feira no parque. Folha de São Paulo: São Paulo, 24 mai. 1968, p.8.

ZANLORENZI, C. M. P. História da Educação, Fontes e a Imprensa. Revista HISTEDBR Online, n.40, p.60-71, dez. 2010. 